\title{
FLEXURAL STRENGTH ESTIMATION FOR HOLLOW CROSS-SECTION SIMPLY SUPPORTED UHPC BEAMS
}

\author{
Nasser Hakeem TU'MA ${ }^{1,{ }^{*},}$ Mohammed Naji HAMMOOD ${ }^{1}$, Rasool Dakhil MOHSIN ${ }^{1}$ \\ ${ }^{1}$ College of Engineering, University of Missan, Misan, Iraq. \\ corresponding author: naserhakeem@uomisan.edu.iq
}

\section{Abstract}

The hollow structural elements occupy a great deal of researchers' interest due to the possibility of losing their weights and maintaining or developing their resistances especially when increasing both compressive and tensile strength of modern materials. The flexural strength based on the forces balance and stain compatibility was derived. Nine beams of Ultra High Performance concrete (UHPC) and conventional reinforced steel bars were casted. Several parameters were taken which are the thickness of the concrete top flange, thickness of the concrete bottom flange, depth of the longitudinal hollow and the ratio of the longitudinal reinforcing steel. By comp aring the practical and theoretical results, the proposed flexural strength provided a safety factor of one-fifth against the experimental collected data. The ultimate flexural force developed up $260 \%$ when increasing the reinforced steel area 4.6 times and $230 \%$ comparing with the solid beam. Many aspect ratios were also mentioned that keep the strength in developing.
\end{abstract}

\author{
Keywords: \\ Hollow cross-section; \\ Flexural strength; \\ Strain compatibility; \\ Concrete flange; \\ UHPC.
}

\section{Introduction}

Generally, subtracting parts of the structural beams while maintaining or developing the strength is very important. Add to that the loss of dead weight leads to increased surface area and possibly increased component efficiency. It also allows the passage of service pipes through them. UHPC has high compressive strength as well as high tensile strength compared to other types of concrete. Many codes differed slightly in evaluating the performance of both strengths.

The design of non-prestressed UHPC called DCTAL was introduced. The idealized compressive stress - strain consisted of multilinear was adopted. The first line was the ascending linear up to $0.85 f_{c}^{\prime}$ with corresponding strain equal to $0.85 f_{c}^{\prime} / E c$. The second part is a constant line had the stress intensity up to stain equal to 0.004 . The last one is the descending part reach to 0.007 strain. The tensile stress-strain curve consisted of bilinear with assumed designed of uniformly stress as 0.4 times the squared root of characteristic strength [1].

Two stress-strain curves of compressive and tensile strength were presented. In case of Service Limit Strength (SLS), the linear relationship was extended to yield stress of $0.6 \mathrm{fc}$. In Ultimate Limit Strength (ULS), the bilinear compressive strength was taken. The ultimate strain was assumed to be 0.003 and the partial safety factor $\gamma_{b f}$ was placed in ULS as account of any manufacturing defects as 1.3. For both cases, the multilinear tensile-stain diagram was plotted [2].

A bilinear compressive stress - strain relationship was adopted. It consisted of two parts. The first line starts from zero stress and strain up to ultimate stress. The second line is the horizontal up to ultimate strain of 0.003. The tensile stress-strain was assumed as uniformly of intensity $0.4 \sqrt{f c^{\prime}}$ [3].

The flexural strength of UHPC beam was examined. The entire section once contained steel fibers, once half contained steel fibers, and a third time was free of fibers. The section was reinforced only with a single longitudinal rebar on the minimum limits depending on $\mathrm{ACl}$ code 318 . Eleven beams were examined, with simple support and with a two point load system of $1.5 \mathrm{~m}$ in length, $250 \mathrm{~mm}$ in depth and $150 \mathrm{~mm}$ in width. The stress distribution is represented in the same way as the US code, 
with a stress intensity of 85 percentage multiplying by characteristic compressive strength over a depth equal to Whitney depth. The maximum strain was taken as 0.0035 . Finally, comparing the strength of experimental and predicated [4].

The ductile behavior was investigated based on flexural strength of UHPC beam reinforced with hybrid Carbon Fiber Reinforced Polymer (CFRP) and steel rebar. The design was according Euro code 2 with RIIME recommendation for tensile strength of $10 \mathrm{MPa}$. The conclusion focused on increasing the failure load by using hybrid reinforcement. It was found that the ductility increased as the section dimensions decreased and the compressive strength increased from 40 to $140 \mathrm{MPa}$ [5].

A partial reinforcement of concrete by PVC pipe to generate a hollow core cross section in the tension zone of RC simply supported beam was carried out $[6,7]$. The flexural strength at various core depths along the beam was investigated. The beam size was $2000 \cdot 200 \cdot 300 \mathrm{~mm}$ with and without hollow core under four point load testing. Hollow core existing performed better flexural strength than conventional solid beams.

The applying of partial uniformly distributed load on six simply supported beams of solid and hollow section was investigated. All beams had the same dimensions of $1000 \mathrm{~mm}$ in length, $180 \mathrm{~mm}$ in height and $120 \mathrm{~mm}$ in width. The opening sizes were $40.40 \mathrm{~mm}$ and $80.80 \mathrm{~mm}$ using styrabor material. The Hollowed beam recorded a decreasing in load carrying capacity of about $58 \%$ when Hollow Ratio was about $14.8 \%$ comparing with the solid beam. The ductility increased when the Hollow ratio decreased to half value [8].

The flexural strength of Steel Fiber Reinforced Concrete (SFRC) rectangular with the circular longitudinal hole was investigated. The size of the beams was $1400 \cdot 150 \cdot 150 \mathrm{~mm}$ of concrete grade of $25 \mathrm{MPa}$. Hollow beams were manufactured by PVC pipes of diameters $32 \mathrm{~mm}, 40 \mathrm{~mm}$ and $50 \mathrm{~mm}$. The hole location was also varied at a distance of 3 to $4 \mathrm{~cm}$ from bottom reinforcement. The cross section and the reinforced tensile ratio were constant for all beams. The crack behaviour and the flexural load were predicted by comparison of experimental results of RC and SFRC [9].

A composite hollow steel box and UHPC was presented for studying the flexural strength. Many parameters were used such as location and the shape of a steel box, longitudinal reinforcement ratio and a number of shear connectors. The location of the steel box varied from mid-high toward the tensile zone of the section. Experimental results showed that the composite hollow beam enhanced the flexural capacity and stiffness than solid beam by $40 \%$ and $23.5 \%$; respectively [10].

The beams that made by High Strength Self-Compacted Concrete (HS-SCC) and longitudinal and transverse opening in beams was used to investigate the flexural strength. The CFRP laminate was adhered around the web openings for crack controlling. Thirteen reinforced concrete (RC) beams were casted and tested. The main objects were to obtain the optimum hollow section and the best position and strengthening for web openings [11].

The experimental residual tensile stress of non-prismatic beam was studied. Thirteen beams were selected as an experimental program to study six main variables in determining shear strength. Stirrups ratio, flexural reinforcement ratio, the volumetric fraction of steel fibers, geometry changing, existing openings along the longitudinal axis, and shear span to depth ratio. According to the tests results, the residual tensile stress was $7 \mathrm{MPa}$ and laying within the most global specifications [12].

\section{Theoretical flexural strength}

In the adopted procedure, the distribution of compressive forces was selected [13]. The depth of the uniformly distributed compressive stress $r$ was determined by strain compatibility, Fig. 1, as follows:

$$
\frac{\varepsilon_{c u}}{C}=\frac{\varepsilon_{c}}{C-r},
$$

$r=\left(1-\frac{\left(\alpha f c^{\prime}\right)}{\varepsilon_{c} \cdot E c}\right) \cdot C$,

where the $\varepsilon_{c u}$ represents the ultimate compressive strain of UHPC and equal to $0.0035, \boldsymbol{\varepsilon}_{c}$ is the stain of concrete at distance of $r$; $E c$ is the modulus of elasticity of UHPC; $C$ is the depth of neutral axis from the extreme compression fiber and $\alpha$ represents the inverse of safety factor of 1.3 multiplying by 0.85 . Then, the compressive forces were derived as

$C_{1}=\left(\alpha f c^{\prime}\right) \cdot b \cdot r$, 
$C_{2}=\frac{1}{2}\left(\alpha f c^{\prime}\right) \cdot\left[(C-r) \cdot b-\left(C-t_{1}\right)\left(b-2 \cdot t_{3}\right)\right]$.

The tensile forces that developed by steel fibers was assumed as uniformly distributed stress $f_{R}$; where $f_{R}$ represents the residual tensile stress and was taken as forty percent of the root of characteristic compressive UHPC [3]

$T_{1}=f_{R}\left[b(h-C)-\left(h-C-t_{2}\right)\left(b-2 t_{3}\right)\right]=f_{R}\left[\sum A_{i} * \bar{y}_{i}\right]$,

where $f_{R}$ represents the residual tensile stress that developed due to existing the steel fibers, $A_{i}$ represents the segments of the area below the neutral axis and $\bar{y}_{i}$ represents the centroid of the corresponding segment of area about the neutral axis. The last tensile force is the yielding rebar force.

$T_{2}=A_{s} \cdot f_{y}$.

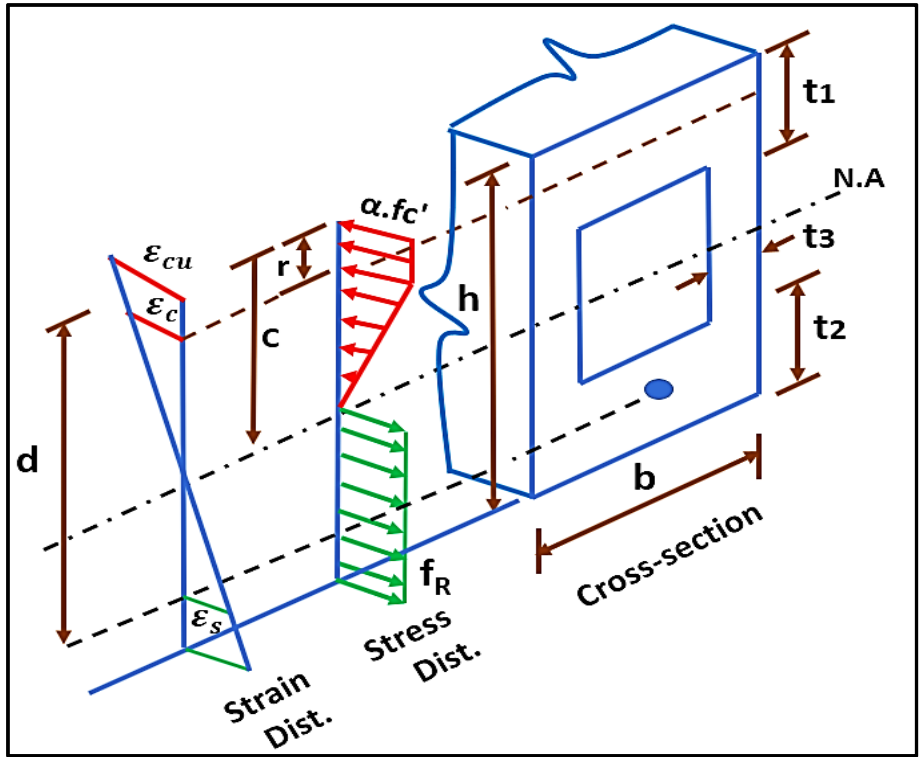

Fig. 1: Stress and strain distribution across the depth.

By equalling the compressive and tensile forces and assume $c$ value to obtain the above forces

$\sum C_{i}=\sum T_{i}$

The flexural strength will obtain by taken moment of all force about neutral axis.

\section{Experimental work}

\subsection{UHPC ingredients}

An ordinary Portland cement type I was used. The fine sand used was imported, DCP Company. Its maximum granule size is $600 \mu \mathrm{m}$ per BS- No. 882 [14]. Micro-silica exhibited granules below $0.1 \mu \mathrm{m}$, which conforms to ASTM C1240-04[15]. The steel fibers have copper-plated, $0.2 \mathrm{~mm}$ in diameter, 13 $\mathrm{mm}$ in length. So, the aspect ratio of 65 . Their ultimate tensile strength is $2800 \mathrm{MPa}$. The optimal mixing was obtained after several trails mixes to get maximum cementous materials quantities (cement + silica fume) and minimum $w / c$ ratios which produced excellent characteristics. The proportion of the mixture used for the structural beams is shown in Table 1. The type of molds used for the samples were $200 \cdot 100 \mathrm{~mm}$ cylinders for measuring compressive strength and splitting tensile strength $f_{c}^{\prime}$ and $f^{\prime} t$, prisms with $100 \cdot 100 \cdot 500 \mathrm{~mm}$ dimensions to measure the modulus of rupture prism tensile strength, Table 2. 
Table 1: Mix proportion for UHPC.

\begin{tabular}{|c|c|c|c|c|c|}
\hline $\begin{array}{c}\text { Cement } \\
{\left[\mathbf{k g} / \mathbf{m}^{3}\right]}\end{array}$ & $\begin{array}{c}\text { Sand } \\
{\left[\mathbf{k g} / \mathbf{m}^{3}\right]}\end{array}$ & $\begin{array}{c}\text { Silica fume } \\
{\left[\mathbf{k g} / \mathbf{m}^{3}\right]}\end{array}$ & $\begin{array}{c}\text { HRWR } \\
{[\%]}\end{array}$ & $\begin{array}{c}\text { W/C } \\
{[\%]}\end{array}$ & $\begin{array}{c}\text { Steel fibers } \\
{\left[\mathbf{k g} / \mathbf{m}^{3}\right]}\end{array}$ \\
\hline 1035 & 920 & 325 & 3 & 0.21 & 157 \\
\hline
\end{tabular}

Table 2: Compressive and tensile strengths.

\begin{tabular}{|c|c|c|}
\hline $\begin{array}{c}\text { Compressive strength } \\
{[\mathrm{MPa}]}\end{array}$ & $\begin{array}{c}\text { Tensile strength (splitting) } \\
{[\mathrm{MPa}]}\end{array}$ & $\begin{array}{c}\text { Tensile strength (prism) } \\
{[\mathrm{MPa}]}\end{array}$ \\
\hline 159.4 & 14.1 & 16.9 \\
\hline
\end{tabular}

\subsection{Steel bars}

Three samples for each diameter were tested for obtaining the yield stress $f_{y}$ and ultimate stress $f_{u}$. The tests were carried out at the Amara Laboratory Technical Institute per ASTM (A615/A615-04a), Table 3.

Table 3: Tensile strengths for reinforced bars.

\begin{tabular}{|c|c|c|c|c|c|c|}
\hline \multicolumn{4}{|c|}{ Test results } & \multicolumn{3}{c|}{ ASTM A 615/A615-04a min. limits } \\
\hline $\begin{array}{c}\text { Bar size } \\
{[\mathrm{mm}]}\end{array}$ & $\begin{array}{c}\text { Yield strength } \\
{[\mathrm{MPa}]}\end{array}$ & $\begin{array}{c}\text { Ultimate strength } \\
{[\mathrm{MPa}]}\end{array}$ & $\begin{array}{c}\text { Elongation } \\
{[\%]}\end{array}$ & $\begin{array}{c}\text { Min. yield strength } \\
{[\mathrm{MPa}]}\end{array}$ & $\begin{array}{c}\text { Min. ultimate strength } \\
{[\mathrm{MPa}]}\end{array}$ & $\begin{array}{c}\text { Elongation } \\
{[\%]}\end{array}$ \\
\hline 10 & 515 & 624 & 31.3 & 420 & 620 & 9 \\
\hline 12 & 552.1 & 654.3 & 32.7 & 420 & 620 & 9 \\
\hline 16 & 571.6 & 657.7 & 32.9 & 420 & 620 & 9 \\
\hline 25 & 581.3 & 673.8 & 33.7 & 420 & 620 & 8 \\
\hline
\end{tabular}

\subsection{Specimens and parameters}

Nine beams were designed to fail in flexural failure. Beams from NB1 to NB2 were reinforced by $2 \Phi 12 \mathrm{~mm}$. Control beam of the solid cross section with same dimensions of depth and width relative to beams of the hollow section. Beam (NB2), was utilized to study the effecting of increasing the depth of the hollow. Beam (NB3) was used to investigate the increasing of both concrete flanges in top and bottom. Beam (NB4) included the increasing the bottom concrete flange and decreasing the top flange. Whiling (NB5) was selected to work vice versa than NB4 (increasing top flange and decreasing bottom flange of UHPC). Beam (NB6) to beam (NB9) were used different percentage of longitudinal reinforcing bars as listed in Table.1. All beams of $1.7 \mathrm{~m}$ in total length and $1.5 \mathrm{~m}$ as clear span were used. The beams have load gap distance of $500 \mathrm{~mm}$ as well as shear span. The width of all beams was $150 \mathrm{~mm}$ and the width of hollow core was $60 \mathrm{~mm}$. Shearing span regions were reinforced by stirrups of $\varnothing 10 \mathrm{~mm}$ each $100 \mathrm{~mm}$ with $20 \mathrm{~mm}$ concrete cover from each side. The ultimate strain was assumed as 0.0035 for all calculations of flexural. The dimensions were chosen to avoid the deflection (controlling) and deep beam limitations, Fig. 2.

Table 4: The details of tested beams.

\begin{tabular}{|c|c|c|c|c|c|c|c|}
\hline $\begin{array}{l}\text { Beam } \\
\text { sign }\end{array}$ & $\begin{array}{c}\text { Top thickness } \\
t_{1}[\mathrm{~mm}]\end{array}$ & $\begin{array}{c}\text { Bottom thickness } \\
t_{2}[\mathrm{~mm}]\end{array}$ & $\begin{array}{c}\text { Section } \\
\text { type }\end{array}$ & $\begin{array}{c}\text { Hollow depth } \\
H[\mathrm{~mm}]\end{array}$ & $\begin{array}{c}\text { Section depth } \\
{[\mathrm{mm}]}\end{array}$ & $\begin{array}{c}\text { Reinforcement area } \\
{\left[\mathrm{mm}^{2}\right]}\end{array}$ & $\begin{array}{l}P_{u, \text { Pred. }} \\
{[\mathrm{kN}]}\end{array}$ \\
\hline NB1 & --- & --- & Solid & 0 & 250 & \multirow{5}{*}{$\begin{array}{l}2 \varnothing 12 \mathrm{~mm}^{2} \\
226 \mathrm{~mm}^{2}\end{array}$} & 161.60 \\
\hline NB2 & 70 & 70 & Hollow & 110 & 250 & & 137.86 \\
\hline NB3 & 80 & 80 & Hollow & 90 & 250 & & 140.65 \\
\hline NB4 & 70 & 90 & Hollow & 90 & 250 & & 143.38 \\
\hline NB5 & 90 & 70 & Hollow & 90 & 250 & & 137.93 \\
\hline NB6 & 70 & 90 & Hollow & 90 & 250 & $\begin{array}{l}3 \varnothing 12 \mathrm{~mm} \\
339 \mathrm{~mm}^{2}\end{array}$ & 179.74 \\
\hline NB7 & 70 & 90 & Hollow & 90 & 250 & $\begin{array}{r}2 \varnothing 16 \mathrm{~mm}^{2} \\
402 \mathrm{~mm}^{2} \\
\end{array}$ & 199.68 \\
\hline NB8 & 70 & 90 & Hollow & 90 & 250 & $\begin{array}{l}3 \varnothing 16 \mathrm{~mm}^{2} \\
603 \mathrm{~mm}^{2}\end{array}$ & 259.36 \\
\hline NB9 & 70 & 90 & Hollow & 90 & 250 & $\begin{array}{c}2 \varnothing 25 \mathrm{~mm} \\
981.75 \mathrm{~mm}^{2}\end{array}$ & 375.25 \\
\hline
\end{tabular}




\subsection{Preparations and testing}

The molds were fabricated from plywood blocks of $18 \mathrm{~mm}$ thick per the proposed dimensions. All the longitudinal hollows were made by compressed cork and extend $100 \mathrm{~mm}$ for each side through the side cover form, Fig. 3.

A horizontal rapid mixer with a vertical shaft was used to overcome on the difficulty of low w/c ratio. The mixing process can be summarized as: mixer.

1) Cementitious material (cement \& silica-fume) were mixed for (1.5 min.) with slow-motion of

2) Slow added of sand over (cementitious), with continue mixing the dry-materials for another (1.5 min.).

3) Mixed together (Water \& HRWR of PC260) and added half of the liquid to admixture for (3 min.) with increase the mixer's speed to medium-motion. (3 min.)

4) Half of remaining-liquid was added slowly to admixture, and continue mixing for another

5) The steel fibers were slowly added (to prevent forming of steel fiber-balls) to mixture (about 1 min.) continued mixing for three minutes to mix steel fibers well with other components.

After concrete placing and curing procedure by boiled water tap in special tank, all beams were painted in white and transform to test.

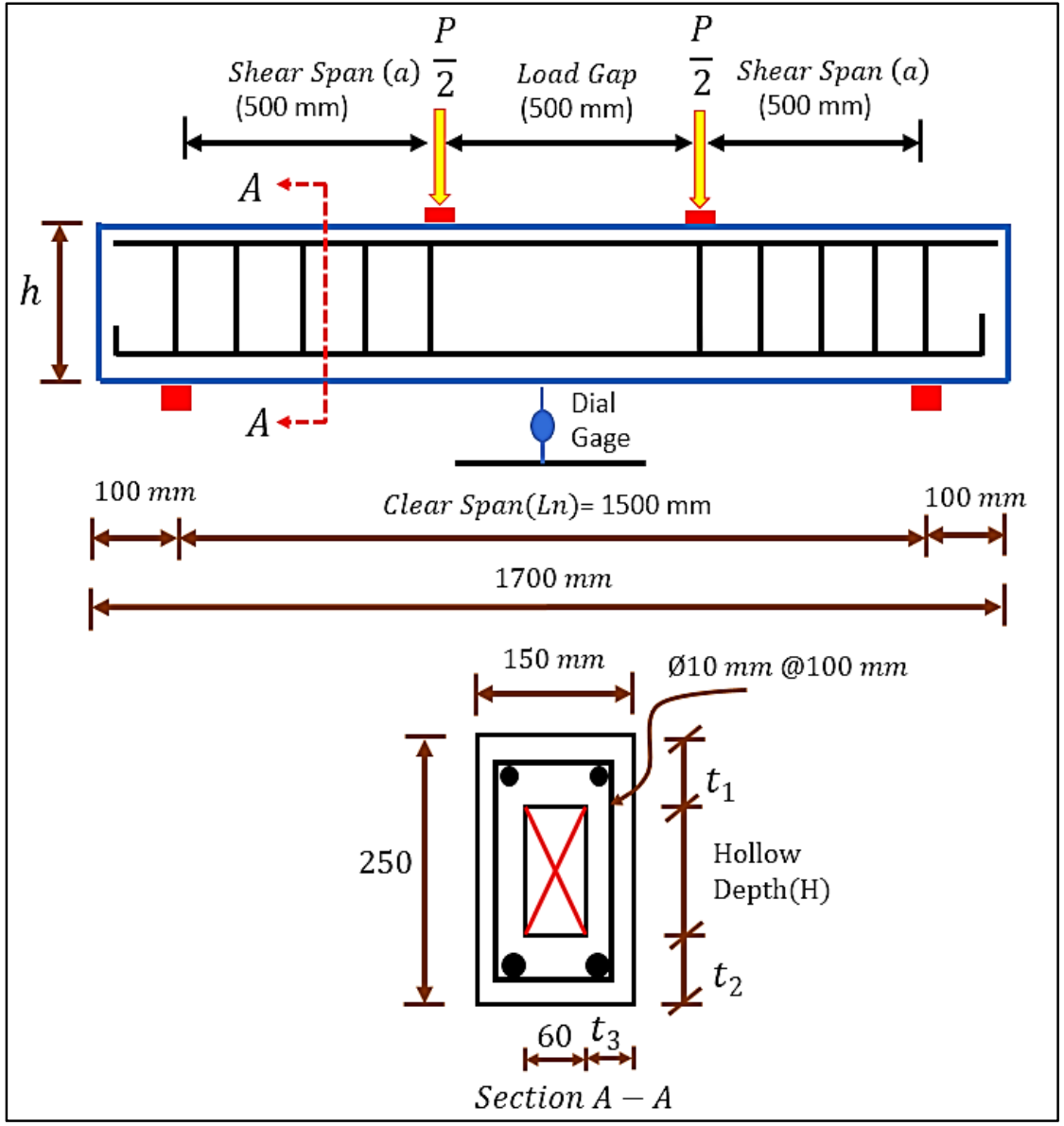

Fig. 2: Geometry and details of tested beams.

The load was applied in the center of the beam specimens with two bearing plates under a twopoint load. The total load capacity is $600 \mathrm{kN}$. The position of dial gages was at the center of the clear span. The dial gauges were INSIZE typed with a maximum measuring of $30 \mathrm{~mm}$ and a precision of $0.01 \mathrm{~mm}$. The loads are applied in successive increments of $5 \mathrm{kN}$ until reaching the failure load. 


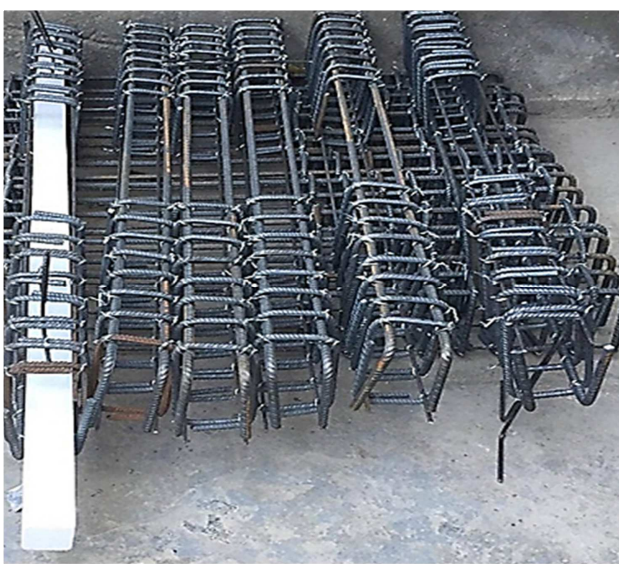

Fig. 3: Fabrication the specimens.

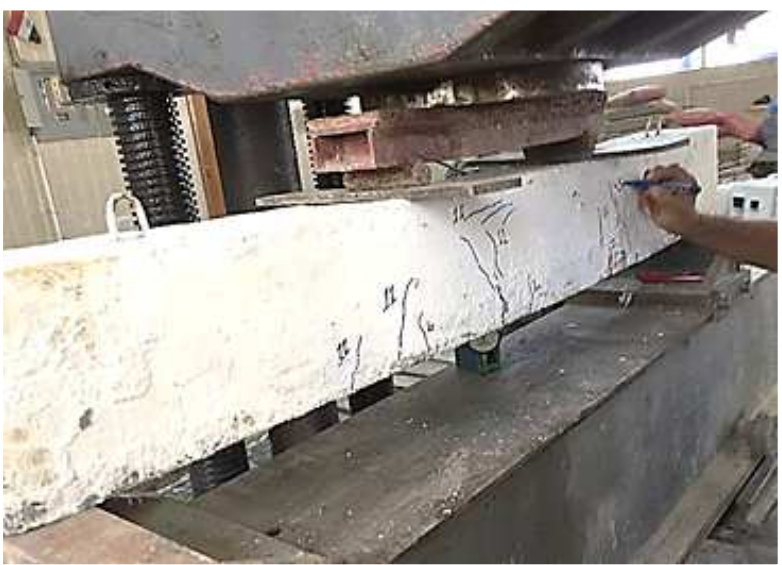

Fig. 4: Testing the specimen.

\section{Results discussion}

For the same amount of the tensile reinforcing area, the specimen of the solid cross section gave higher ultimate load relative to four beams (NB2 to NB5). The reason may be due to increasing the flexural component of existing the steel fibers. For the others beams of the hollow cross section, NB2 to NB5, all beams had nearly the same strength and the same hollow depth but Beam NB4 of 70 $\mathrm{mm}$ thickness in top concrete flange and $90 \mathrm{~mm}$ thick in bottom was higher value. This may be due to randomly distributed of steel fibers. So, the minimum aspect ratio of top concrete thickness to overall depth of the cross section $t_{1} / h=70 / 250$ was equal to 0.28 that keep the specimen in sufficient strength. The maximum aspect ratio of hollow depth to overall thickness $H / h=110 / 250$ was noticed to be 0.44 or the maximum ratio of hollow area to the area of the overall cross section will be $18 \%$. Therefore, the possibility of saving $18 \%$ of the concrete volume when comparing to cost issue can be achieved. The same crack pattern has been seen for all beams and the crushing in extreme fiber had finally done. The difference of $20 \%$ between the ultimate proposed load and ultimate experimental load had determined, Table 2 and Fig. 5.

Beams NB6 to NB9 were used for studying the increasing the amount of tensile steel area. When increasing the tensile area of rebar from $2 \varnothing 12 \mathrm{~mm}\left(226 \mathrm{~mm}^{2}\right)$ to $2 \varnothing 25 \mathrm{~mm}\left(982 \mathrm{~mm}^{2}\right)$, the ultimate strength force has a higher value. So, for the same dimension of the beam and size of the hollow core, the increasing of reinforcing steel ratio to 4.3, the ultimate flexural load increasing in $260 \%$ (NB9 and NB4). Also, the increasing of the steel ratio of NB9 and NB1, the increasing of ultimate load of $230 \%$ for the hollow beam comparing with the solid beam.

Table 5: Proposed and experimental ultimate loads.

\begin{tabular}{|c|c|c|c|c|c|c|c|}
\hline Beam & $\boldsymbol{C}_{\mathbf{1}}[\mathbf{k N}]$ & $\boldsymbol{C}_{\mathbf{2}}[\mathbf{k N}]$ & $\boldsymbol{T}_{\mathbf{1}}[\mathbf{k N}]$ & $\boldsymbol{T}_{\mathbf{2}}[\mathbf{k N}]$ & $\begin{array}{c}\boldsymbol{P}_{u, P r e d .} \\
{[\mathbf{k N}]}\end{array}$ & $\begin{array}{c}\boldsymbol{P}_{u, \text { Exp. }} \\
{[\mathbf{k N}]}\end{array}$ & $\begin{array}{c}\boldsymbol{P}_{u, \text { Exp. }} / \boldsymbol{P}_{u, \text { Pred. }} \\
{[\%]}\end{array}$ \\
\hline NB1 & 136.80 & 127.03 & 170.33 & 93.64 & 161.60 & 130.5 & 80.76 \\
\hline NB2 & 120.76 & 112.13 & 139.23 & 93.64 & 137.86 & 113.5 & 82.33 \\
\hline NB3 & 123.70 & 114.86 & 144.88 & 93.64 & 140.65 & 115 & 81.76 \\
\hline NB4 & 123.70 & 114.86 & 144.88 & 93.64 & 143.38 & 115.5 & 80.56 \\
\hline NB5 & 123.70 & 114.86 & 144.88 & 93.64 & 137.93 & 112 & 81.20 \\
\hline NB6 & 146.32 & 135.87 & 141.73 & 140.47 & 179.74 & 144.5 & 80.40 \\
\hline NB7 & 158.89 & 147.54 & 139.98 & 166.48 & 199.68 & 163 & 81.63 \\
\hline NB8 & 199.16 & 184.94 & 134.37 & 249.72 & 262.32 & 208 & 79.29 \\
\hline NB9 & 274.97 & 255.33 & 123.82 & 406.44 & 375.25 & 301.5 & 80.35 \\
\hline
\end{tabular}




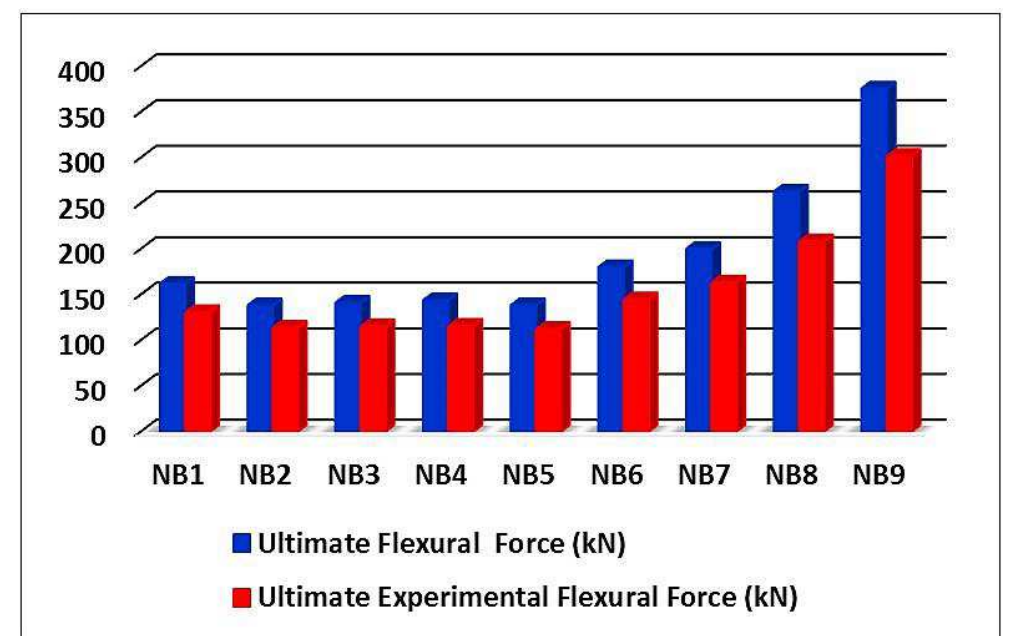

Fig. 5: Ultimate experimental and proposed flexural force.

The proposed total compressive forces and individual tensile force were shown in Fig. 6 . It clear that in low percentage of the reinforcing steel bars, the contribution of steel fibers of the volumetric fraction of $2 \%$ reaches to $13 \%$. This percentage remains when the strength develops by adding steel bars quantity because it depends on the sizes of the cross section and hollow core as well as the assumed intensity of residual tensile stress.

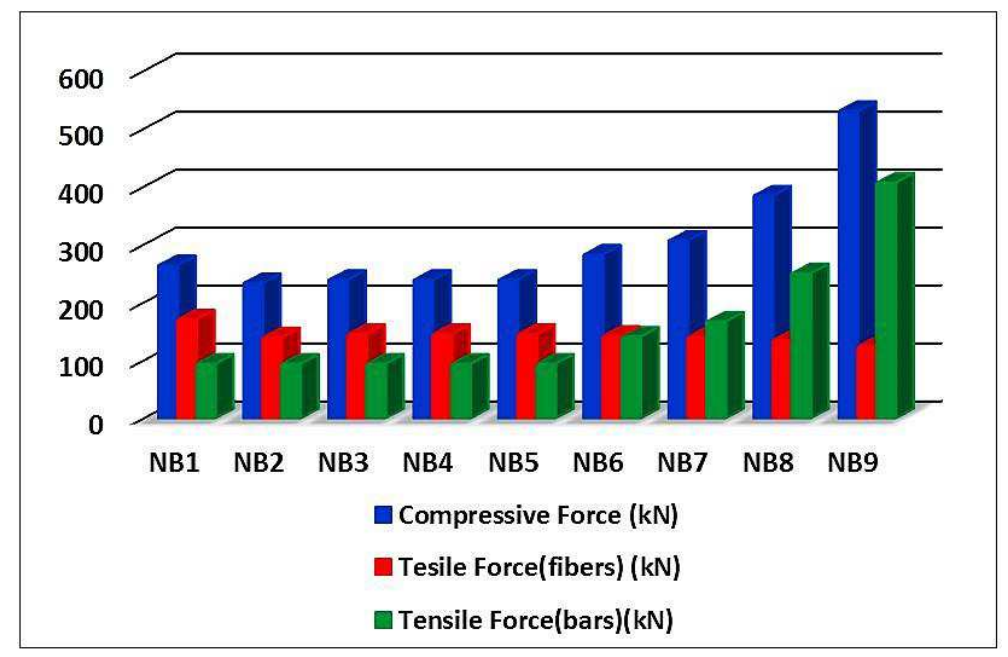

Fig. 6: Compressive and tensile flexural forces.

Also, the details of individual strength of each flexural strength's components were shown in Fig. 7. For all beam, the main component that carries the most strength is the rebar component. The component of steel fibers corporates in the second stage. While the compression zone of UHPC will be responsible on relatively small amount of strength. That is mean, the minimization of concrete top flange thickness was preferred for economical flexural performance. 


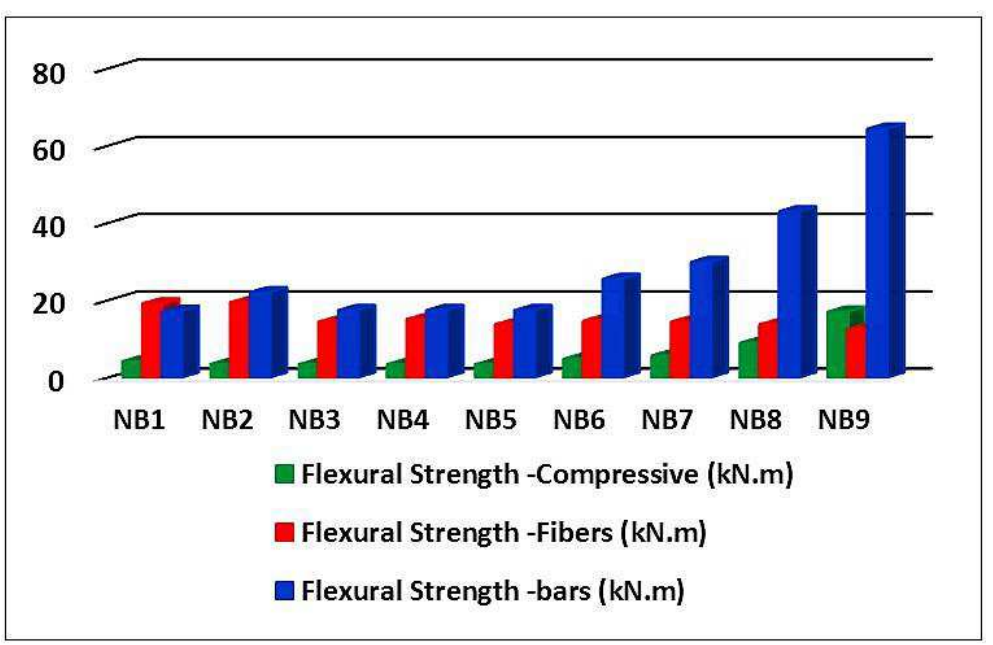

Fig. 7: Components of flexural strength.

The load - deflection curve of UHPC beams differs from the normal concrete curve in that the cracking load cannot be easily distinguished. The curve behavior begins as an almost straight line, then the curve behavior begins as non-linear behavior. The behavior of NB1 to NB5 is similar. Beams from NB7 to NB9 were significantly different in terms of stiffness, toughness and ductility. It can be seen that the slop of the lower part of curve increases, indicating an increase in stiffness. Therefore, the NB9 has a higher stiffness than others. The same applies to the area under the curve that represented by Toughness, as well as the behavior of post- crack which express as ductility.

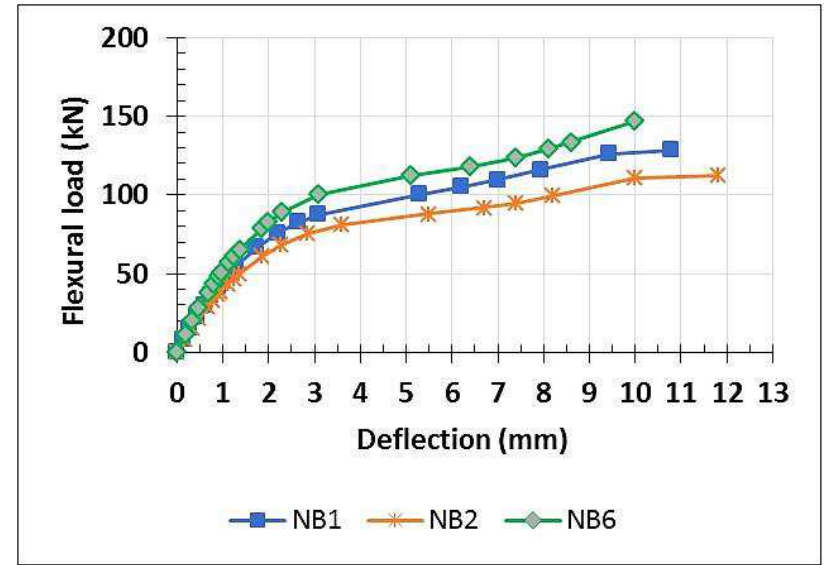

Fig. 8: Load - mid span deflection relation.

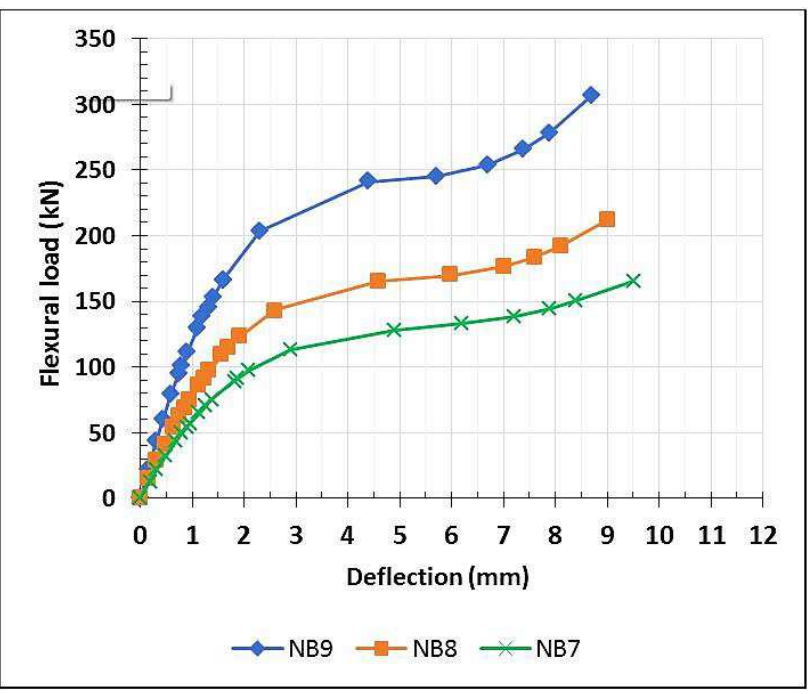

Fig. 9: Load - mid span deflection relation. 


\section{Conclusion}

The flexural strength based on the forces balance and strain compatibility was estimated. It provides $1 / 5$ a safety factor against the experimental records. The maximum permitted one layer of longitudinal reinforcing bars of the hollow beam enhances the flexural strength up to $260 \%$ when increasing the tensile reinforcing area to 2.6 times and $230 \%$ comparing with the solid beam. Also, the minimum aspect ratio of top concrete flange to the beam depth was $28 \%$ regardless the changing the bottom of the concrete flange or the depth of hollow opening. The maximum aspect ratio of bottom concrete flange to section's depth $t_{2} / h$ was $36 \%$ that keep the higher values of flexural strength, stiffness, toughness and ductility. The volumetric excluding as ratio of concrete volume to the hollow was $17 \%$. For all beams, the proposed flexural component of steel fibers contributes in decreasing when increasing the rebar amount and varies from $13 \%$ of total strength for low amount and $40 \%$ for more. Furthermore, the theoretical neutral axis was within the concrete permitted top flange for all beams and can sustain for wide range of developing compressive forces.

\section{References}

[1] GOWRIPALAN, N. - IAN, R. G.: Design Guidelines for Ductal Prestressed Concrete Beams. Reference Article, the University of NSW, Australia, 2000.

[2] JSCE: Recommendations for Design and Construction of Ultra High Strength Fiber Reinforced Concrete Structures-Draft, 2004.

[3] ALMANSOUR, H. - LOUNIS, Z.: Design of prestressed UHPFRC girder bridges according to Canadian Highway Bridge Design Code. International Workshop on Ultra High Performance Fiber Reinforced Concrete (UHPFRC), France, 2009.

[4] WASAN, I. K.-TAYFUR, Y. R.: Flexural Strength of Fibrous Ultra High Performance Reinforced Concrete Beams, ARPN Journal of Engineering and Applied Sciences, Vol. 8, No. 3, 2013.

[5] SI-LARBI, A. - FERRIER, E. - HAMELIN, P.: Flexural Behavior of Ultra High Performance Concrete reinforced with mixed short fibers and CFRP rebars.Ultra High Performance Concrete (UHPC), International Symposium on Ultra High Performance Concrete, pp. 661-672, Kassel University, Germany, 2004.

[6] NIBIN, V. - ANUP, J.: Flexural Behavior of Reinforced Concrete Beam with Hollow Core at Various Depth. International Journal of Science and Research (IJSR), Vol. 5, Iss. 5, May 2016.

[7] DHINESH, N. P. - SATHEESH, V. S.: Flexural Behaviour of Hollow Square Beam. International Journal of Scientific Engineering and Applied Science (IJSEAS), Vol. 3, Iss. 3, 2017.

[8] AHMAD, J. H. - HADI, N. G.: Structural Behavior of Reinforced Concrete Hollow Beams under Partial Uniformly Distributed Load. Journal of Engineering, Vol. 20, No. 7, 2014.

[9] BIBI, M. J. - BINCY, S.: Parametric Study of Longitudinal Hollow Steel Fibre Reinforced Concrete (SFRC) Beams. IOP Conf. Series: Materials Science and Engineering, 2018.

[10] NASSER, H. T. - MUSTAFA, R. A.: Flexural Strength Estimation for Composite UHPC-Tubular Steel Beam. Journal of Engineering Science and Technology, Vol. 3, Iss. 15, 2020.

[11] YAARUB, G. A. - HUSSAIN, D. A.: Structural Behavior of HS-SC Reinforced Concrete Beams with Longitudinal and Transverse Openings Strengthened with CFRP Laminates. Journal of Engineering and Sustainable Development, Vol. 22, No. 05, 2018.

[12] NASSER, H. T. - MUSTAFA, R. A. - HAIDER, J. B.: Residual Tensile Stress Estimation for Shear Strength of UHPC Nonprismatic Beams. Civil and Environmental Engineering, Vol. 17, Iss. 1, 2021, pp. 164-177.

[13] SETRA/AFGC: Ultra High Performance Fiber-Reinforced Concrete, 2002.

[14] B.S. 882: Specification for Aggregates from Natural Sources for Concrete. British Standards Institute, 1992.

[15] ASTM C1240-04: Standard Specification for the Use of Silica Fume as a Mineral Admixture in Hydraulic Cement Concrete. Mortar and Grout, Vol. 4.2, 2004, p. 6. 